tributions correspond to a range of temperatures from 5.2 to $6.3 \mathrm{keV}$, in excellent agreement with the predicted thermonuclear value of $5 \mathrm{keV}$.

\section{The prevalence of chaos}

\section{from N. MacDonald}

IT has been known since the time of Poincaré that quite simple conservative dynamical systems, such as two coupled linear oscillators, can exhibit highly complicated behaviour. As well as periodic trajectories, which are closed curves in phase space, there are also trajectories which, loosely speaking, fill up volumes in phase space. The rather special nature of conservative systems limits the number of physical contexts in which this behaviour can be manifested. (For some interesting examples see Henon \& Heiles Astr. J. 69, 73; 1964; Dunnett, Laing \& Taylor J. math. Phys. 9, 1819; 1968.) Analogous behaviour has been observed in recent years in a number of nonlinear models of physical systems which are open or dissipative, rather than conservative. This is leading to reappraisal of our understanding of these systems.

The best known example is that put forward by E. N. Lorenz (J. atmos. Sci. 20, 130; 1963). He starts from the partial differential equations for flow in a layer of liquid of uniform depth with a constant temperature difference maintained between the upper and lower surfaces. These have a steady state solution with zero flow. As the temperature difference is raised this solution becomes unstable and convective flow solutions replace it. Lorenz examines one particular mode of convective flow, and uses a truncated Fourier expansion to reduce the problem to one involving three coupled ordinary differential equations. The variables are the intensity of convective flow, the temperature difference between ascending and descending currents, and a quantity measuring the departure from linearity of the temperature gradient across the fluid layer. Lorenz finds a second instability, beyond which the simple smooth convective flow is replaced by an extremely complex and unpredictable flow. The mathematics of this situation have become popular in the past few years, and progress in understanding the nature of the complex flow is reviewed in the proceedings of a seminar

$N$. MacDonald is in the Department of Natural Philosophy in the University of Glasgow.

\title{
The blind fishes of Persia
}

THE note published in News and Views $(264,113 ; 1976)$ on the blind cave fishes of Persia mentioned the discovery of the two cavernicolous forms Noemachilus smithi (Cobitidae) and Iranocypris typhlops (Cyprinidae) in the same well-like outlet. This is of great interest for the zoogeographical and etho-ecological interpretation of the possible mechanisms which led epigean fishes to colonise subterranean waters and evolve underground into isolated homogeneous populations composed entirely of eyeless and depigmented individuals. These phenomena of regressive evolution have been well studied on several populations inhabiting caves (Thinès L'èvolution régressive des Poissons cavernicoles et abyssaux, Masson, Paris, 1969), but little, if any, specific attention has been given to the case of cavernicolous forms found in wells and artificial outlets. It is therefore fortunate that $\mathrm{Mr}$ Smith was able to discover this new Noemachilus form in association with the previously discovered Iranocypris (Brunn \& Kaiser Dan. Scient. Invest. Iran, Munksgaard, Copenhagen, 1943). However, the coexistence of two distinct regressed species in the same well has been observed before. In 1962, Mees found two diffenent blind and depigmented Teleosts, Milyeringa veritas (Gobiidae) and Anommatophasma candidum (Synbranchidae) in two wells depending on the same subterranean system and located about 10 miles apart, near Yardee Creek Station, North West Cape, Australia (Mees J. R. Soc. West. Austr. 45, (I), $24 ; 1962)$.

The coexistence of distinct cavernicolous forms in a same biotope other than a cave, raises the question of the exact nature and extent of their habitat. Underground waters can be traced with sufficient precision in many karstic systems (the system of sinks, underground caverns and streams found in limestone areas), whereas water sheets feeding wells or pumping sites do not lend themselves to similar descriptions. In addition, such phreatic water tables cannot be explored by speleologists, so that the only topographical data are those furnished by geological surveys. Thus, biospeleologists have had to limit themselves to inference as far as the

on turbulence held at Berkeley in 1975 (Springer Lecture Notes in Mathematics No. 615 ; 1977.)

The conditions for this new instability are physically unattainable in this experiment. However, H. Haken has habitat is concerned. The only sound hypothesis about regressed fishes found in wells and other artificial water outlets is that these forms normally live in the phreatic sheets and are occasionally attracted to zones exposed to light by organic remnants of animal or human origin. The fact that fishes of the same species are sometimes observed in wells separated by a great distance is, in my opinion, the strongest argument in favour of this view. Mees reported the presence of the free-swimming Milyeringa in only two of the three wells he visited (Milyering, Kudmurra and Tandabiddi, the last halfway between and some 10 miles from the other two), whereas the eel-like Anommatophasma was found in all three sites. The cases of Iranocypris typhlops and of Noemachilus smithi seem similar to that of Milyeringa veritas. The ecological conditions in which these fishes live are moreover similar to those reported as early as 1904 by Goeldi for Phreatobius cisternarum (Goeldi Rept. 6th Int. Zool. Congr. Bern, 549; 1904), a very peculiar catfish belonging to the family Trichomycteridae which he found in a cistern of Marajo Island in the mouth of the Amazon and which was rediscovered recently (Delamare, personal communication). I have collected specimens of the blind Clariidae Uegitglanis zammaranoi in the canalisations of the Iscia-Baidoa pumping station (Somaliland) some 60 miles from the well of Uegit, where the first specimens were discovered in 1923 by Gianferrari (Atti. Soc. Ital. Sc. Nat. Mus. Civ. Stor. Nat. Milano, 62; 1923). To the present day, this distance is by far the greatest to have been reported for the geographical extension of a cavernicolous fish not dwelling in a cave (Thinès Rev. Zool. Bot. Afric. 57, 117; 1958). The case of Noemachilus smithi can thus be considered as a typical instance of an already well-known phenomenon, whose meaning for biospeleological research is clear.

\section{G. THINÈS}

CPEC Animal Behaviour,

Louvain University

3041 Pellenberg

Belgium

pointed out (Phys. Lett. 53A, 77; 1975) a remarkable parallel between the Lorenz model and a classical approximation to the dynamics of a single mode laser. In this case the three variables are the field strength and polar- 